University of South Carolina

Scholar Commons

Faculty Publications

Electrical Engineering, Department of

3-1-2005

\title{
Study and Design of a Capacitively Coupled Polymeric Internal
}

\section{Antenna}

Khan M.Z. Shams

University of South Carolina - Columbia, shams@engr.sc.edu

Mohammod Ali

University of South Carolina - Columbia, alimo@engr.sc.edu

Follow this and additional works at: https://scholarcommons.sc.edu/elct_facpub

Part of the Electrical and Computer Engineering Commons

\section{Publication Info}

Published in IEEE Transactions on Antennas and Propagation, Volume 53, 2005, pages 985-993.

http://ieeexplore.ieee.org/xpl/Recentlssue.jsp?punumber=8

(c) 2005 by IEEE

This Article is brought to you by the Electrical Engineering, Department of at Scholar Commons. It has been accepted for inclusion in Faculty Publications by an authorized administrator of Scholar Commons. For more information, please contact digres@mailbox.sc.edu. 


\title{
Study and Design of a Capacitively Coupled Polymeric Internal Antenna
}

\author{
Khan M. Z. Shams and Mohammod Ali, Senior Member, IEEE
}

\begin{abstract}
A capacitively coupled polymeric internal antenna is introduced for Bluetooth or GPS applications. Such an antenna can be easily fabricated on a flexible film substrate and attached to the inside surface of the plastic housing of a portable wireless device, such as a PDA. The proposed antenna saves critical space on the printed circuit board (PCB) and eliminates the need for a vertical contact feed. Thus manufacturing is also simplified and cost is reduced. Practical examples of utilizing such a concept for Bluetooth $(2.45 \mathrm{GHz})$ and GPS (1.575 GHz) applications are provided. The antenna system requires a small coupling plate (as small as 4 by 4 $\mathrm{mm}^{2}$ ) that can be easily surface mounted on a PCB. The solution proposed provides wideband operation satisfying Bluetooth functionality with good radiation pattern and gain.
\end{abstract}

Index Terms-Antenna, capacitively-coupled, internal, polymeric, wireless.

\section{INTRODUCTION}

W ITH the rapid growth of wireless communications there is an increasing demand for portable wireless devices that are small, attractive, lightweight, and stylish. This has resulted in the proliferation of portable device antennas that are internal or hidden within the device [1]-[18]. Along with antennas for mobile phone applications in the AMPS, GSM, DCS, and PCS bands [19] many wireless devices are coming with Bluetooth or wireless local area network (WLAN) functionalities incorporated within them. While for the phone frequency bands, a reasonably large sized planar inverted-F antenna is required, for Bluetooth application a small surface-mounted inverted-F antenna is generally adequate [16], [17]. Such an antenna is printed on an FR4 substrate and can be accommodated within a volume of $25 \mathrm{~mm}$ by $4 \mathrm{~mm}$ by $3 \mathrm{~mm}$ where the last dimension being the height.

However, since the antenna has to be mounted on the printed circuit board (PCB) surface and a $3 \mathrm{~mm}$ or higher height from the $\mathrm{PCB}$ is generally required there were some other alternative solutions proposed [16]-[18]. In [16], [17] an integrated inverted-F antenna was proposed which was printed on the PCB surface itself. This required the creation of a small window where no other metal was allowed other than the antenna. In [18] a flexible film type packaged inverted-F antenna was introduced that was integrated with the plastic stylus holder of a personal digital assistant.

Manuscript received March 2, 2004; revised May 25, 2004. This work was supported in part by the National Science Foundation (NSF) Career Award ECS0237783.

The authors are with the Department of Electrical Engineering, University of South Carolina, Columbia, SC 29208 USA (e-mail: alimo@engr.sc.edu).

Digital Object Identifier 10.1109/TAP.2004.842650
In this paper, we present a capacitively coupled polymeric internal antenna for Bluetooth or GPS application. The proposed antenna assembly occupies very little space on the PCB (as small as a $4 \mathrm{~mm}$ by $4 \mathrm{~mm}$ square on a varying substrate height of $1-3 \mathrm{~mm})$. This small element is nothing but a surface mount coupling plate that can be manufactured and installed the same way present day chip antennas [20] are manufactured and installed on wireless device PCBs. The actual radiating element lies at a distance above it and is fed capacitively using this plate. Since the radiating element is not on the PCB, it is not susceptible to shielding cans or other metal objects nearby.

The proposed radiating element can be fabricated on a flexible film substrate such as liquid crystal polymer (LCP) from Rogers Corporation and then adhesively bonded to the inside plastic cover of the device. The absence of any physical connection with the actual radiating element makes this design simple, easy, and cost-effective to manufacture. Design examples covering both the Bluetooth $(2.4-2.485 \mathrm{GHz})$ and GPS $(1.575 \mathrm{GHz})$ frequencies are given.

\section{ANTENNA CONFIGURATION}

The geometry of the proposed antenna is shown in Fig. 1. There are three metal layers. In the first layer lies the PCB which measures $90 \mathrm{~mm}$ by $70 \mathrm{~mm}$. The coupling plate is located on the second layer. The actual antenna is on the third layer. The complete structure in an actual usage scenario should be flipped upside down with the antenna side on the top. The antenna is printed on an LCP film and then adhesively bonded to the inside back cover of the device. The dimensions of the coupling plate vary from $4 \mathrm{~mm}$ by $4 \mathrm{~mm}$ to $8 \mathrm{~mm}$ by $8 \mathrm{~mm}$ depending on the type of application, Bluetooth or GPS. The coupling plate is surface mounted on one edge of the PCB. For simplicity of modeling the coupling plate has been shown to be in air and is connected to the PCB using a vertical post [see Fig. 2(a)]. In reality, it will be a small surface mount plate on FR4 substrate with a plated thru hole at its center that can connect to the RF port of the radio. The dimensions of the coupling plate, the height of the coupling plate from the PCB $(h 1)$, and the antenna height from the coupling plate $(h 2)$ are critical parameters that need to be studied in order to achieve a successful design.

\section{REsUlts}

\section{A. Bluetooth/WLAN Antenna}

1) Initial Study: Design and analysis of the antenna were conducted using IE3D. First, the Bluetooth/IEEE 802.11b 


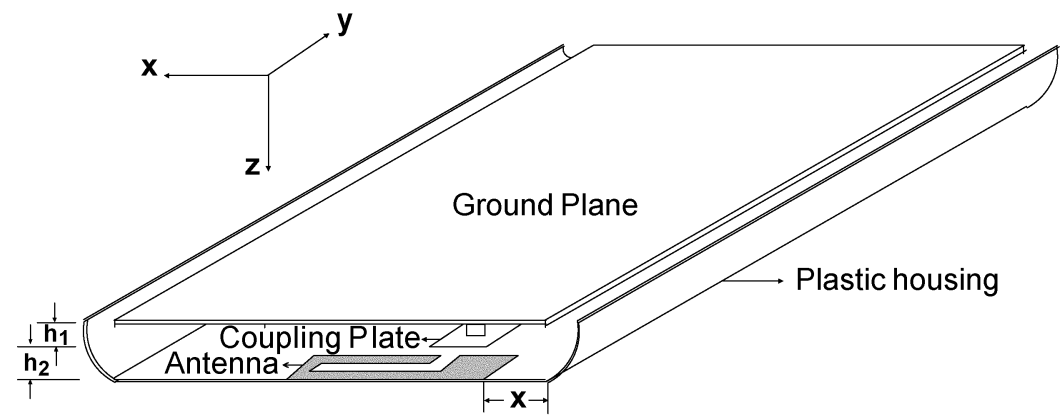

Fig. 1. Geometrical configuration of the proposed antenna.

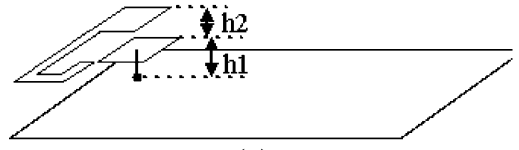

(a)

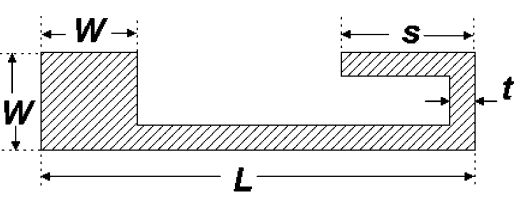

(b)

Fig. 2. For Bluetooth application. (a) Simulated geometry. (b) Parameters of the radiating element.

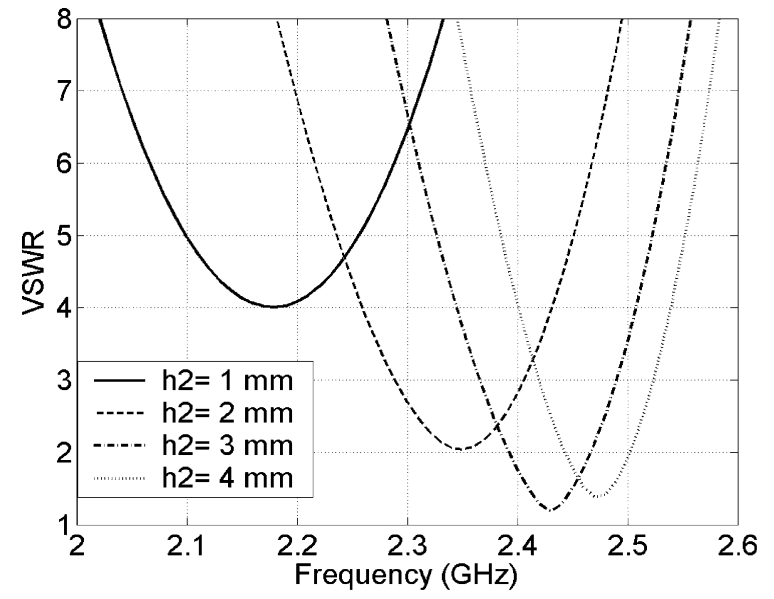

(a)

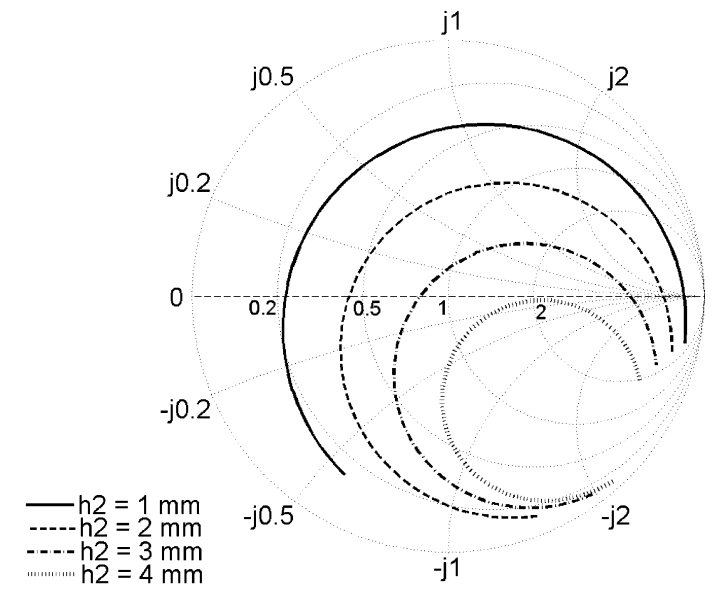

(b)

Fig. 3. Effect of antenna height $h 2$ on (a) VSWR and (b) impedance. Antenna parameters: $h 1=3, x=10$, coupling plate size $=8$ by $8, W=8, L=36$, $s=10.7$, and $t=2 \mathrm{~mm}$.

operating frequency band of $2.4-2.485 \mathrm{GHz}$ was considered. The configuration modeled and analyzed is shown in Fig. 2. A ground plane size of $90 \mathrm{~mm}$ by $70 \mathrm{~mm}$ was selected which is representative of a typical personal digital assistant (PDA). The simulation geometry is shown in Fig. 2(a). A coupling plate size of $8 \mathrm{~mm}$ by $8 \mathrm{~mm}$ was considered. The height of the plate is $3 \mathrm{~mm}$ (fixed) from the ground plane. The geometry of the radiating element is shown in Fig. 2(b). The plate measuring $W$ by $W$ lies right on top of the coupling plate. The edge of the coupling plate is $10 \mathrm{~mm}$ away from the edge of the ground plane. The overall size of the antenna is $L$ by $W$ $\mathrm{mm}^{2}$. Other parameters are $t$, width of the antenna trace and $s$, length of the bent element. Note that the resonance frequency and bandwidth of the antenna depend on $L, t, s$, and $W$. No particular attempt was taken to miniaturize the antenna at this point. A trace width $t=2 \mathrm{~mm}$ and $L=36 \mathrm{~mm}$ was selected which resulted in $s=10.6 \mathrm{~mm}$ for the antenna to achieve resonance at $2.45 \mathrm{GHz}$. The antenna height from the coupling plate was $h 2=3 \mathrm{~mm}$.
2) Input Impedance and VSWR: Input impedance was computed as a function of frequency with $h 2$ as the parameter. Computed VSWR and input impedance as function of $h 2$ are shown in Fig. 3. It is apparent that reducing $h 2$ reduces the resonant frequency of the antenna and deteriorates the VSWR performance. The resonant frequencies are $2.48,2.43,2.35$, and $2.2 \mathrm{GHz}$, respectively, for $h 2=4,3,2$ and $1 \mathrm{~mm}$. Corresponding VSWR at these frequencies are 1.5, 1.3, 2, and 4, respectively. Considering a VSWR upper limit of 2.5:1 the antenna bandwidth is $100 \mathrm{MHz}$ for $h 2=3 \mathrm{~mm}$. The degradation in antenna VSWR and bandwidth can be explained from the impedance plots of Fig. 3(b). Decreasing $h 2$ decreases the impedance. The impedance locus for $h 2=1 \mathrm{~mm}$ has a large spread with frequency compared to the loci for other $h 2$ values. The resistance at the primary resonance is also low $(12 \Omega)$ for this case. Both of these are indicative of poor impedance match and narrow bandwidth. In contrast, the resistance for $h 2=3 \mathrm{~mm}$ is $40 \Omega$ at the primary resonance. A small $h 2$ makes the antenna very tightly coupled to the coupling plate strengthening the capacitive near field effect while 


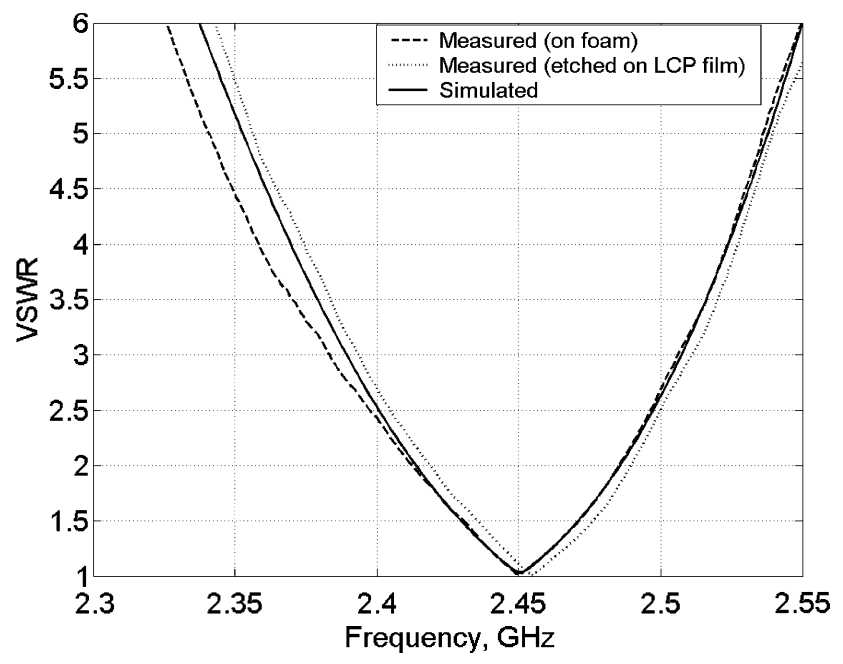

Fig. 4. Comparison of measured and computed VSWR data for Bluetooth application.

weakening the radiating far field effect. This results in a degradation of the resonant resistance and a spread in the impedance locus. Thus clearly for this particular case, an antenna height, $h 2$ of 3 to $4 \mathrm{~mm}$ should be a good choice. It was found that $h 2=3.4 \mathrm{~mm}$ provided the best results. Bandwidth achieved was $95 \mathrm{MHz}$. At this height, the impedance passes through the center of the Smith chart and provides the lowest VSWR at 2.45 $\mathrm{GHz}$. Considering the bandwidth requirement for Bluetooth is 2.4-2.485 GHz this provides some room for tolerance.

Next, two antenna prototypes were fabricated and measured. First, an antenna resembling the simulated design was fabricated. It had the following parameters: $h 1=3, h 2=3.4$, $x=10, W=8, L=36, s=10.7$, and $t=2 \mathrm{~mm}$. The coupling plate was placed on a 3-mm-thick piece of Rohacell foam $\left(\varepsilon_{\mathrm{r}}=1.04\right)$. A hole was drilled at the center of the plate and through the PCB. An SMA connector was then used to feed the coupling plate. The inner conductor of the connector was soldered to the coupling plate while the outer conductor was connected to the ground. Another piece of foam with height $3.5 \mathrm{~mm}$ was placed on the coupling plate on top of which the antenna was glued. For the second antenna the coupling plate and the connection methodology was unchanged. The actual radiating element was printed on a very thin liquid crystal polymer (LCP) film. The antenna was then attached to the inside back cover of a plastic device housing. This ensemble was then positioned on top of the coupling plate at a height of $h 2=3.5 \mathrm{~mm}$. Due to the dielectric loading the antenna dimension was adjusted to achieve resonance. The length was reduced accordingly. We call the data for the antenna fabricated on foam "Measured (on foam)" and the data for the antenna fabricated on LCP film "Measured (etched on LCP film)." The simulated data corresponds to the antenna on foam. The measured data is compared with the simulated data in Fig. 4. The agreement between the computed and measured data for both cases is quite good. Computed and measured resonant frequencies are about the same. Bandwidth is only very slightly wider for the antenna on foam.
TABLE I

ANTENNA BANDWIDTH SENSITIVITY AS FunCTION ANTENNA HEIGHT $(h 2)$. ANTENNA PARAMETERS: $h_{1}=3.0, x=10$, coupling plate size $=8$ BY 8 , $W=8, L=36, s=10.7$, and $t=2 \mathrm{~mm}$

\begin{tabular}{c|c}
\hline $\begin{array}{c}\text { Height of the antenna } \\
\text { from the ground plane, } \\
\text { h2 mm }\end{array}$ & $\begin{array}{c}\text { Bandwidth, MHz } \\
\text { (VSWR } \leq 2.5)\end{array}$ \\
\hline 3.0 & 100 \\
\hline 3.2 & 98 \\
\hline 3.4 & 95 \\
\hline 3.6 & 91 \\
\hline 3.8 & 87 \\
\hline
\end{tabular}

Since in an actual manufacturing environment there could be some variation in the parameter, $h 2$ we studied the antenna sensitivity as function of $h 2$. The parameter $h 1$ is fairly tightly controlled since it will be a surface mount piece on standard FR4 substrate. We varied $h 2$ as $3,3.2,3.4,3.6$, and $3.8 \mathrm{~mm}$. These results are listed in Table I. The median height being $3.4 \mathrm{~mm}$ if $h 2$ has a tolerance of $\pm 0.4 \mathrm{~mm}$ the bandwidth varies between 87 to $100 \mathrm{MHz}$ which is still within the required bandwidth for Bluetooth.

Next, the effect of the coupling plate height, $h 1$ is studied. For this $h 2=3.4 \mathrm{~mm}$ is kept constant and $h 1$ is varied as 1,2 , and 3 $\mathrm{mm}$. These results are shown in Fig. 5. Clearly, reducing $h 1$ does not deteriorate antenna impedance as much as it does when $h 2$ is reduced. Thus, it appears that it is the coupling between the plate and the radiating element that is crucial. Because irrespective of whether $h 1$ or $h 2$ is reduced the distance between the ground plane and the antenna can be maintained fixed. For instance for $h 1=3 \mathrm{~mm}$ and $h 2=1 \mathrm{~mm}$ the VSWR data given in Fig. 3 is not at all close to the data for $h 1=1 \mathrm{~mm}$ and $h 2=3.4 \mathrm{~mm}$ shown in Fig. 5. Note that for the first case the distance between the antenna and the ground plane is $4 \mathrm{~mm}$, while for the second it is $4.4 \mathrm{~mm}$. Thus clearly reducing $h 1$ to a much smaller value is possible. This, however, moves the impedance to the high impedance region which can be further improved by increasing $h 2$.

Effect of the coupling plate size was studied next. Plate sizes of $8 \times 8,6 \times 6$, and $4 \times 4 \mathrm{~mm}^{2}$ were considered. It is clear from Fig. $6(\mathrm{~b})$ that reducing the coupling plate size increases the input impedance. This is probably due to undercoupling. Observing Figs. 6 and 3 one may infer that the adverse effect of reducing the coupling plate can be compensated by reducing $h 2$. However, in that case the overall height of the portable device housing from the ground plane may become too small. Essentially, $h 1+h 2$ together should provide some reasonable physical distance so that other components and chips can be mounted on the PCB. It appears that the $6.4 \mathrm{~mm}$ height we considered in the beginning is a reasonable value.

3) Radiation Pattern and Gain: Computed radiation patterns for the antenna on foam are shown in Fig. 7. Patterns were computed at $2.45 \mathrm{GHz}$. In the $x z$-plane $\left(\varphi=0^{\circ}\right.$ plane) the E-phi component has a dipole like pattern with the beam maximum along $\theta=90^{\circ}$. However, this is not the dominant component and is below about $10 \mathrm{~dB}$ of the E-theta component. The E-theta component is more directional. Its beam peak is directed toward the zenith $\left(\theta=0^{\circ}\right)$. The front to back ratio is 


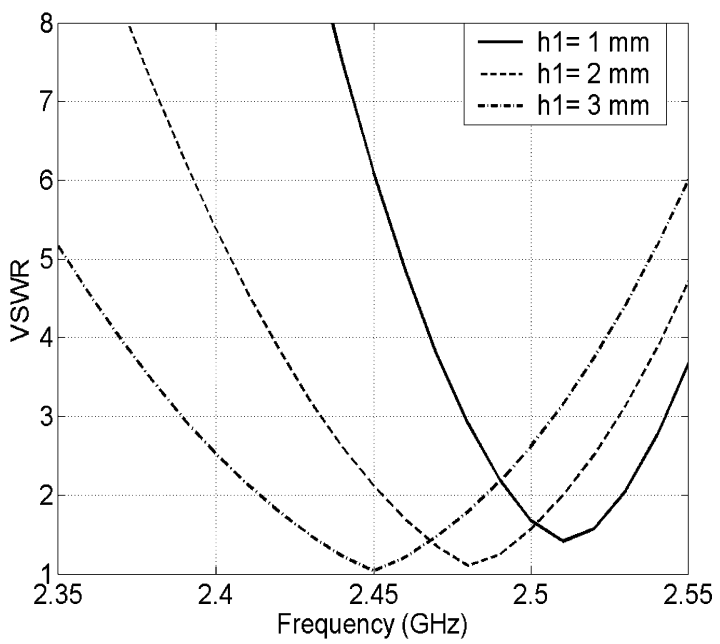

(a)

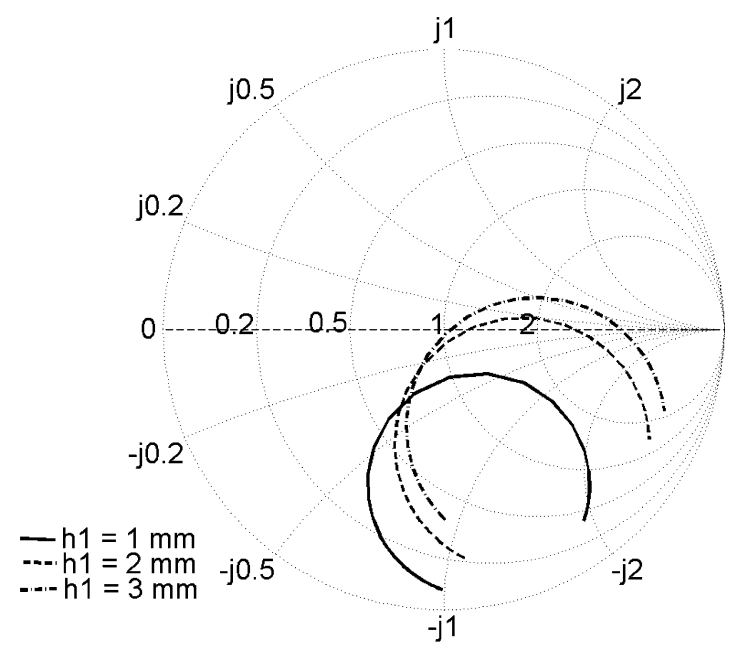

(b)

Fig. 5. Effect of coupling plate height $\left(h_{1}\right)$ on (a) VSWR and (b) impedance. Antenna parameters: $h_{2}=3.4, x=10$, coupling plate size $=8$ by $8, W=8$, $L=36, s=10.7$, and $t=2 \mathrm{~mm}$.

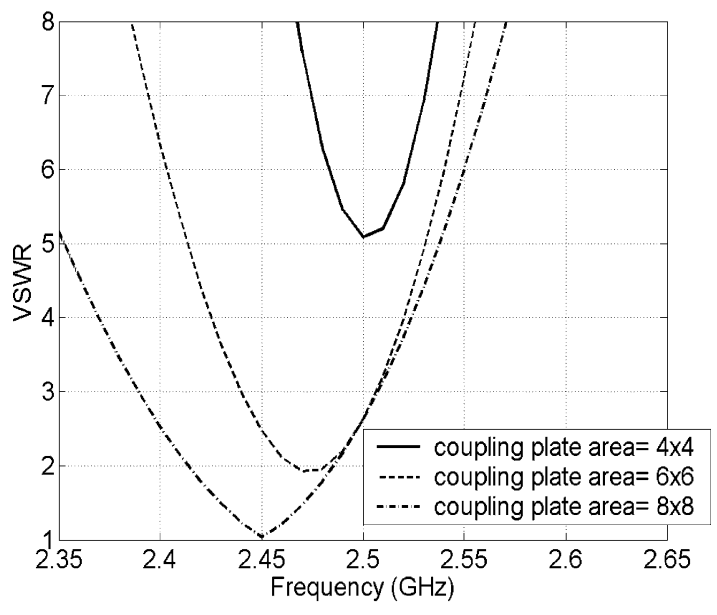

(a)

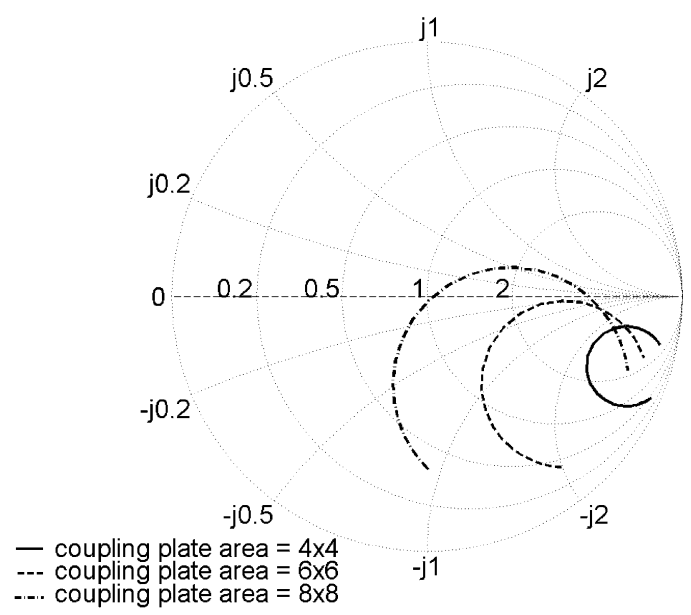

(b)

Fig. 6. Effect of coupling plate size on $t=2 \mathrm{~mm}$.

(a) VSWR and (b) impedance. Antenna parameters: $h_{1}=3, h_{2}=3.4, x=10, W=8, L=36, s=10.7$, and

$12 \mathrm{~dB}$. The $3-\mathrm{dB}$ beamwidth is about $70^{\circ}$. Clearly, the antenna pattern reminds us of the pattern of a directional patch antenna. In the $y z$-plane $\left(\varphi=90^{\circ}\right.$ plane $)$ the E-phi component is the dominant one while the E-theta component is suppressed below $20 \mathrm{~dB}$. The $3 \mathrm{~dB}$ beamwidth extends from $-120^{\circ}$ to $+35^{\circ}$ providing a coverage region of $155^{\circ}$. Thus clearly the antenna provides a wide angular coverage region. For instance, when the device is used in the talk position the antenna beam will clearly face the horizon [see Fig. 1, the antenna is on the opposite side of the user's head] and will provide an excellent coverage angle of $155^{\circ}$ in the opposite direction of the user's head. Also the higher antenna peak gain of $5.5 \mathrm{dBi}$ at $2.45 \mathrm{GHz}$ will serve as an advantage compared to surface mount chip antennas with gain of about $2 \mathrm{dBi}$ [20]. When the device is hold in a slanted position some of the radiation will be directed toward the ground. However, since mobile wireless devices all operate in a nonline of sight (NLOS) multipath environment the reflected waves from the ground will experience similar multipath effects as a cellular phone antenna and should provide adequate coverage. In essence, the proposed antenna will have very similar performance as a mobile phone internal antenna [14], [15].

\section{B. GPS Antenna}

1) Input Impedance and VSWR: To test the feasibility of the proposed concept for GPS (global positioning system) application for handheld devices some simulations were conducted. According to the Federal Communications Commission guidelines most mobile phone makers are in the process of incorporating GPS functionalities in their phones to support enhanced 911. Since GPS satellites transmit right-hand circularly polarized (CP) waves it is clear that if linearly polarized antennas are used the received signal strength will be low. However, the challenging task of designing and incorporating a miniaturized, high-gain, internal CP antenna within a handheld device is moving designers to linearly polarized internal 


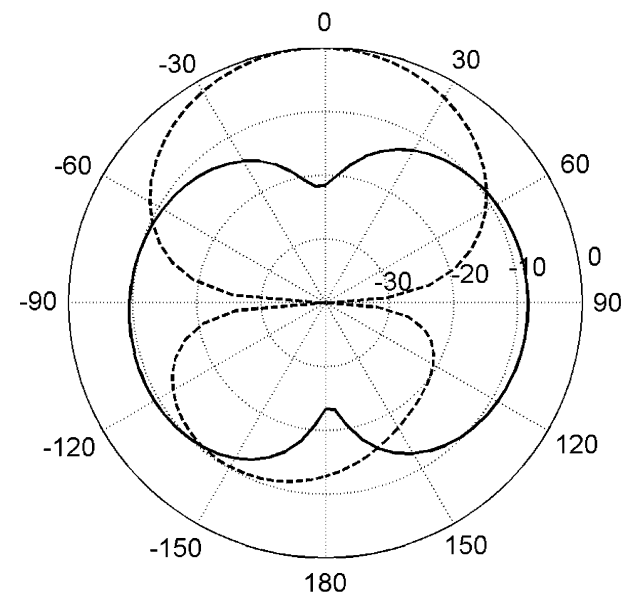

(a)

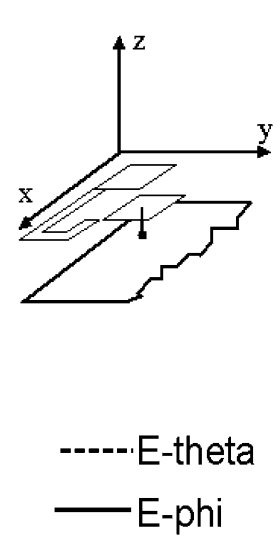

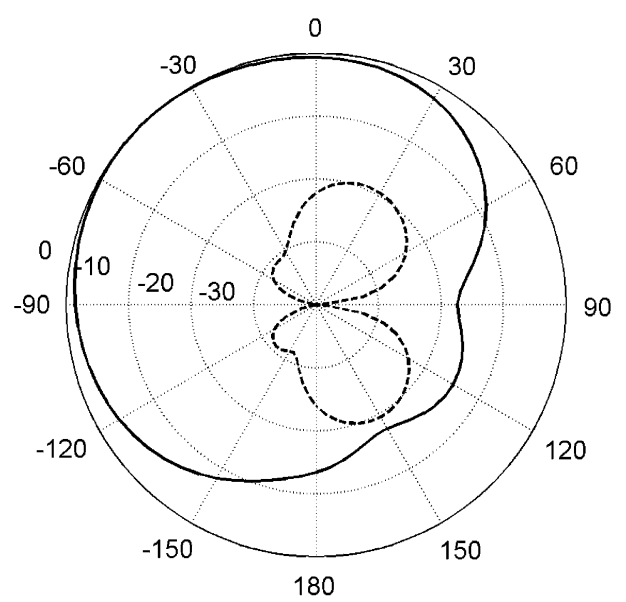

(b)

Fig. 7. Normalized radiation patterns at $2.45 \mathrm{GHz}$. (a) $\phi=0^{\circ}$ plane. (b) $\phi=90^{\circ}$ plane. Antenna parameters: $h_{1}=3, h_{2}=3.4, x=10$, coupling plate size $=$ 8 by $8, W=8, L=36, s=10.7$, and $t=2 \mathrm{~mm}$.

antenna solutions particularly for base station assisted GPS applications [21].

To design the linearly polarized internal antenna for GPS application, the same ground plane size of $90 \mathrm{~mm}$ by $70 \mathrm{~mm}$ was selected. The coupling plate size was reduced to $4 \mathrm{~mm}$ by 4 $\mathrm{mm}$. We have already seen that reducing the coupling plate size reduces the VSWR bandwidth [Fig. 6(a)] and it also increases the input impedances [Fig. 6(b)]. However, for GPS application, narrow bandwidth is not a problem and undercoupling due to reduction in coupling plate size can be overcome by reducing the antenna height from the coupling plate. For GPS application, the antenna needs to operate at $1575.42 \mathrm{MHz}$ with a few $\mathrm{MHz}$ of bandwidth for tolerance. The coupling plate is located close to the PCB. Therefore, reducing the coupling plate size provides more space for circuits on the PCB.

The geometry of the radiating element for GPS application is shown in Fig. 8. The overall size of the antenna is $L$ by $W \mathrm{~mm}$. The parameters of this antenna are $W, L, t, s, Q$, and $R$ [Fig. 8]. The height of the coupling plate from the ground plane is $3 \mathrm{~mm}$ as before. The antenna is placed on top of the coupling plate at a distance of $1 \mathrm{~mm}$. Initially, $L=36 \mathrm{~mm}, W=8 \mathrm{~mm}$, $t=2 \mathrm{~mm}, s=26 \mathrm{~mm}, Q=5 \mathrm{~mm}$, and $R=14 \mathrm{~mm}$ was found to achieve resonance at $1.575 \mathrm{GHz}$.

Computed VSWR and input impedance data with $h 2$ as parameter are shown in Fig. 9 which follows the same trend as for the Bluetooth antenna. Increasing $h 2$ increases the resonant frequency. Clearly, an optimum $h 2$ is required to achieve a proper impedance match. To achieve resonance at $1.575 \mathrm{GHz}$, the antenna dimensions can be adjusted.

2) Radiation Pattern and Gain: Radiation pattern data for the GPS antenna with $L=36, W=8, t=2, s=26, Q=5$, $R=14, h 1=3$, and $h 2=1 \mathrm{~mm}$ were computed at $1.575 \mathrm{GHz}$. It was observed that peak gain was only $0.16 \mathrm{dBi}$. Computed patterns are shown in Fig. 10. Comparing Figs. 5 and 10 it is apparent that the directional nature of the Bluetooth patterns are absent in the GPS patterns. This is part of the reason for peak gain degradation. Initially, we thought that perhaps the smaller coupling plate size is contributing to the gain degradation. A

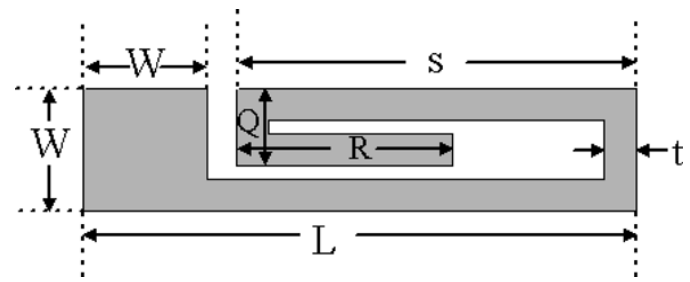

Fig. 8. Detailed parameters of the radiating element for GPS application.

study was conducted for both Bluetooth and GPS antennas for which the coupling plate size was varied. The coupling plate height was fixed at $h 1=3 \mathrm{~mm}$ while $h 2$ and other antenna parameters were varied to achieve resonances at 2.45 and 1.575 GHz. These results are listed in Table II. Clearly, the coupling plate size change has negligible effect on the antenna gain.

Next, we decided to focus on altering the GPS antenna geometrical shape with the assumption that oppositely directed currents in the closely spaced elements in Fig. 8 might be the reason for field cancellation and gain degradation. Note that this problem did not manifest in Fig. 2 for Bluetooth. For GPS operation the antenna length needed to be increased which resulted in the shape shown in Fig. 8. Thus, several geometries were considered as listed in Table III. Antennas A and B resonate at the same frequency $1.575 \mathrm{GHz}$. It is possible to avoid the closely spaced elements of antenna A yet achieve resonance at 1.575 $\mathrm{GHz}$ by making $t=0.5 \mathrm{~mm}$ with antenna $\mathrm{B}$. Peak gain increases by $0.5 \mathrm{~dB}$. Note that neither antenna is optimized for low VSWR. With antennas $\mathrm{C}$ and D considerable improvement in antenna peak gain is observed. Peak gain is 2.4 and $2.5 \mathrm{dBi}$, respectively. However, the antenna length is much larger. Antenna $\mathrm{E}$ on the other hand provides negative gain of $0.8 \mathrm{dBi}$. Comparing all antennas of Table III it is clear that antennas A, B, and $\mathrm{E}$ are not properly matched to achieve low VSWR. This was ensured next by varying $h 2$. These results are listed in Table IV. Evidently by adjusting $h 2$ the VSWR of antennas A, B, and E can be reduced to as small as $1.1,1.16$, and 1.05 , respectively. Corresponding peak gain values are $0.16,1.05$, and $1.05 \mathrm{dBi}$. Thus clearly antenna B is a better choice. It also substantiates 


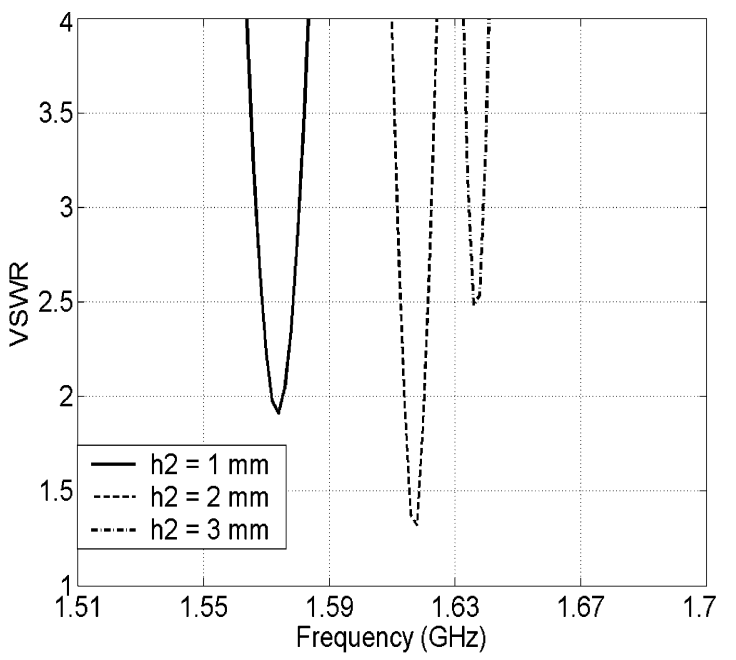

(a)

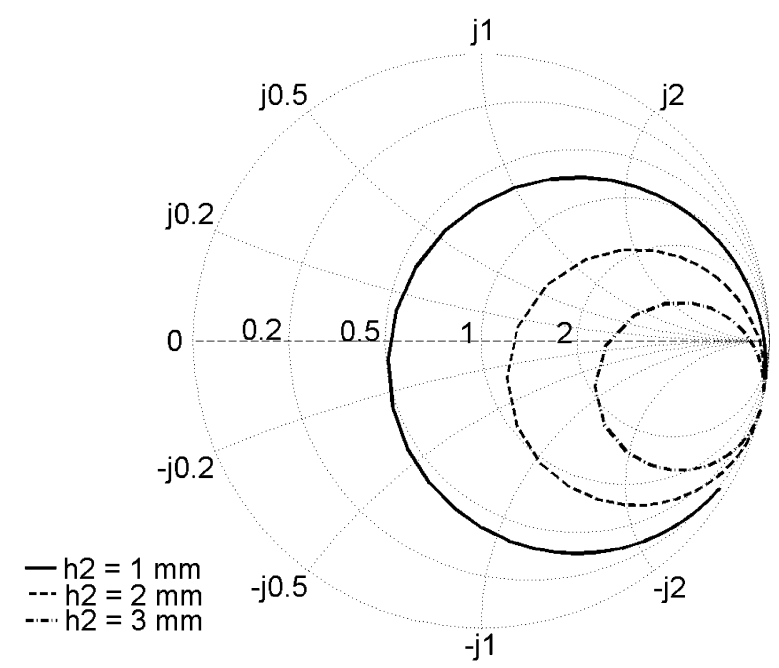

(b)

Fig. 9. Effect of antenna height from coupling plate ( $h 2$ ) on (a) VSWR and (b) impedance. Antenna parameters: $h_{1}=3.0, x=10$, coupling plate size $=4$ by $4, W=8, L=36, s=26, Q=5, R=14$, and $t=2 \mathrm{~mm}$.

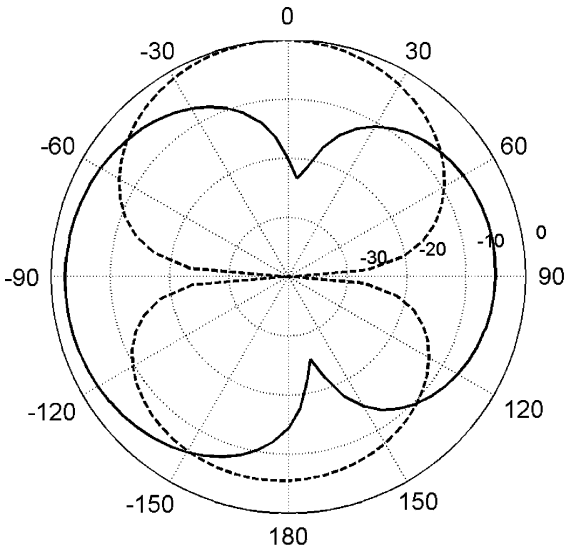

(a)

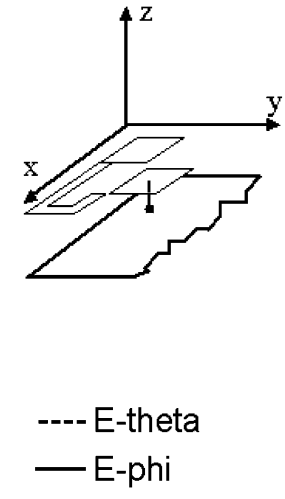

$-120$

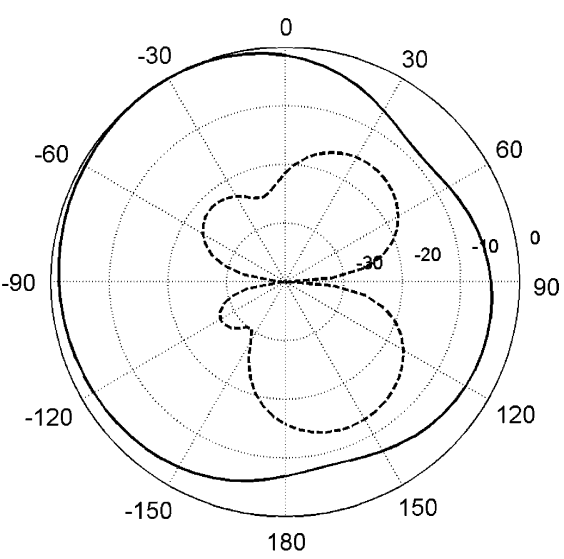

(b)

Fig. 10. Radiation patterns at $1.575 \mathrm{GHz}$ for (a) $\phi=0^{\circ}$ plane. (b) $\phi=90^{\circ}$ plane. Antenna parameters: $h_{1}=3.0, h 2=1, x=10$, coupling plate size $=4$ by $4, W=8, L=36, s=26, Q=5, R=14$, and $t=2 \mathrm{~mm}$.

TABLE II

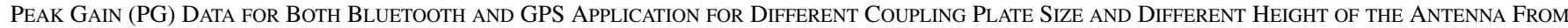
THE COUPLing Plate $(h 2), h 1=3 \mathrm{~mm}$

\begin{tabular}{c|c|c|c}
\hline $\begin{array}{c}\text { Frequency, } \mathrm{f} \\
(\mathrm{GHz})\end{array}$ & $\begin{array}{c}\text { Coupling plate size } \\
\text { in mm by mm }\end{array}$ & $\begin{array}{c}\text { Height of the antenna from } \\
\text { the ground plane, } \mathrm{h} 2 \mathrm{~mm}\end{array}$ & $\begin{array}{c}\text { Peak Gain, } \\
\mathrm{dBi}\end{array}$ \\
\hline \multirow{2}{*}{2.45} & $8 \times 8$ & 3.4 & 5.6 \\
\cline { 2 - 4 } & $6 \times 6$ & 2.3 & 5.5 \\
\cline { 2 - 4 } & $4 \times 4$ & 1.0 & 5.4 \\
\hline \multirow{3}{*}{1.575} & $8 \times 8$ & 3.4 & 0.63 \\
\cline { 2 - 4 } & $6 \times 6$ & 2.3 & 0.41 \\
\cline { 2 - 4 } & $4 \times 4$ & 1.0 & 0.16 \\
\hline
\end{tabular}

our earlier hypothesis that the closely spaced elements with opposite currents result in far-field cancellation and eventual peak gain degradation for antenna A.

Based on this information GPS antenna prototypes were fabricated and tested for VSWR. These results are shown in Fig. 11. Measured bandwidth is about $20 \mathrm{MHz}$, while computed bandwidth is about $13 \mathrm{MHz}$. This difference in bandwidth may be due to the variation of $h 2$ for the experimental prototypes.
3) Influence of Surface Mount Chips on Antenna Performance: To observe the effect of surface mount chips on antenna performance simulations were conducted considering the scenario shown in Fig. 12. Several 3-mm-high chips were modeled. Two cases were considered. First, a single chip was positioned near the antenna and its effect on the VSWR was studied for both Bluetooth and GPS. Second, three chips were placed on the PCB among which two of them were positioned 
TABLE III

VSWR And the Peak Gain Data for Different Antenna Shape for 1.575-GHz Frequency. The Antenna Parameters: Coupling Plate Size 4 mm BY $4 \mathrm{~mm}, h 1=3 \mathrm{~mm}, h 2=1.00 \mathrm{~mm}$

\begin{tabular}{|c|c|c|c|}
\hline Antenna type & Shape of the antenna & VSWR & Peak Gain, $\mathrm{PG}, \mathrm{dB}$ \\
\hline A & 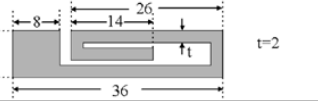 & 1.9 & 0.16 \\
\hline B & $\rightarrow-8 \rightarrow \overbrace{f_{2.9}}-26 \longrightarrow+=0.5$ & 2.0 & 0.6 \\
\hline $\mathrm{C}$ & $\begin{array}{l}1 \\
t=0.5 \\
1\end{array}$ & 1.2 & 2.4 \\
\hline D & $\frac{10.5}{1}-60$ & 1.2 & 2.5 \\
\hline E & $8 \rightarrow \square$ & 2.52 & -0.8 \\
\hline
\end{tabular}

TABLE IV

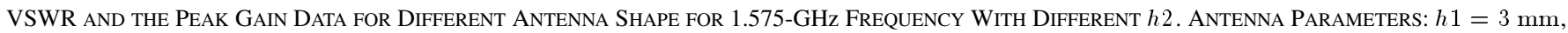
the Coupling Plate Size is $4 \mathrm{~mm}$ By $4 \mathrm{~mm}$

\begin{tabular}{l|l|l|l|l}
\hline $\begin{array}{l}\text { Antenna } \\
\text { type }\end{array}$ & Shape of the antenna & $\begin{array}{l}\text { Height of the antenna } \\
\text { from the coupling } \\
\text { plate, h2 mm }\end{array}$ & VSWR & $\begin{array}{l}\text { Peak Gain, } \\
\text { PG, dB }\end{array}$ \\
\hline $\mathrm{A}$ & 1.65 & 1.1 & 0.16 \\
\hline $\mathrm{B}$ & & 1.82 & 1.16 & 1.05 \\
\hline $\mathrm{E}$ & & & & \\
\hline
\end{tabular}

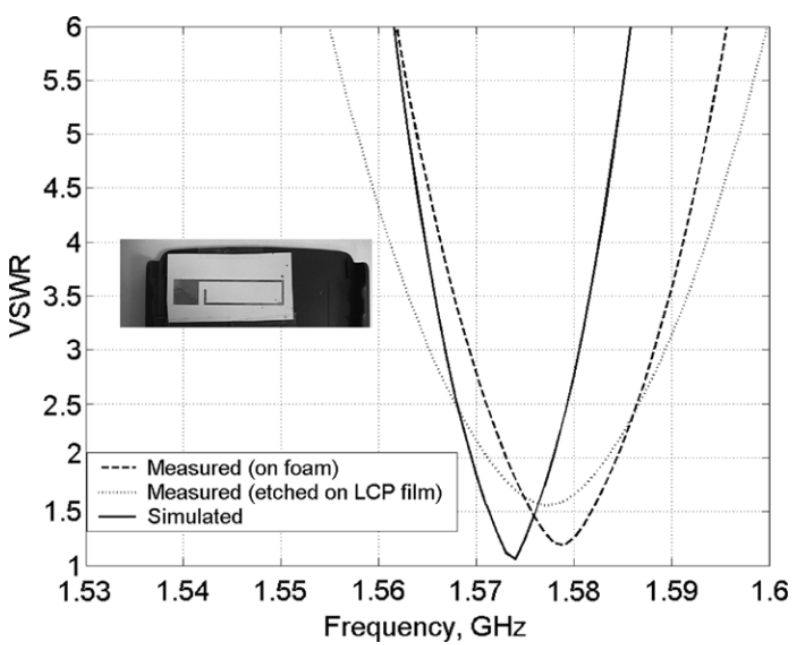

Fig. 11. Comparison of measured and computed VSWR data for GPS application. Antenna parameters: $h_{1}=3.0, h 2=2, x=10$, coupling plate size $=4$ by $4, W=8, L=36, s=26$, and $t=0.5 \mathrm{~mm}$.

just underneath the antenna trace. The schematics of the two cases are shown in Fig. 12(a) and (c). Corresponding VSWR plots are shown Fig. 12(b) and (d), respectively. The presence of the chips slightly changes the antenna VSWR. The change in the operating frequency is within $50 \mathrm{MHz}$ for Bluetooth while within $5 \mathrm{MHz}$ for GPS. However, depending on the number of chips, their sizes, and the location with respect to the antenna, the antenna trace length can be appropriately adjusted to ensure proper operation at the frequency band of interest.

\section{DISCUSSION}

A capacitively coupled polymeric internal concept is described and demonstrated for possible application for Bluetooth/IEEE $802.11 \mathrm{~b}$ and GPS. The proposed scheme helps save valuable printed circuit board space which can be used to mount various circuit elements. As described the surface mount coupling plate can be as small as 4 by $4 \mathrm{~mm}^{2}$. The antenna can be easily printed on an LCP film and then adhesively bonded to the inside back cover of the device housing. Polyimide film can also be used but since they absorb moisture there is a potential for change in the resonant frequency of the antenna. Antenna bandwidth is adequate for $2.4-2.485 \mathrm{GHz}$ Bluetooth or WLAN application. Antenna gain is also very good (larger than $5 \mathrm{dBi}$ at $2.45 \mathrm{GHz}$ ). Fabricated prototypes on foam and LCP film substantiate the computed data.

Results for GPS application indicate that the antenna has more than adequate bandwidth. A detailed study of the antenna gain issue was conducted. It is concluded that the peak gain is generally lower than the Bluetooth case primarily due to the lower operating frequency. The ground plane does not provide 


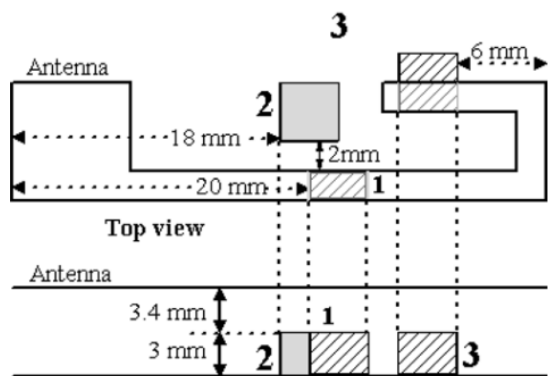

Cross-sectional View
Chip 1: $2 \times 4 \mathrm{~mm}^{2}$ Chip-2: $2 \times 2 \mathrm{~mm}^{2}$ Chip-3: $2 \times 2 \mathrm{~mm}^{2}$

(a)
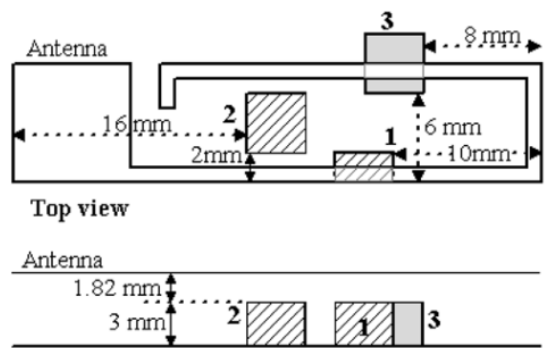

Cross-sectional View
Chip 1: $2 \times 4 \mathrm{~mm}^{2}$ Chip-2: $2 \times 2 \mathrm{~mm}^{2}$ Chip-3: $2 \times 2 \mathrm{~mm}^{2}$

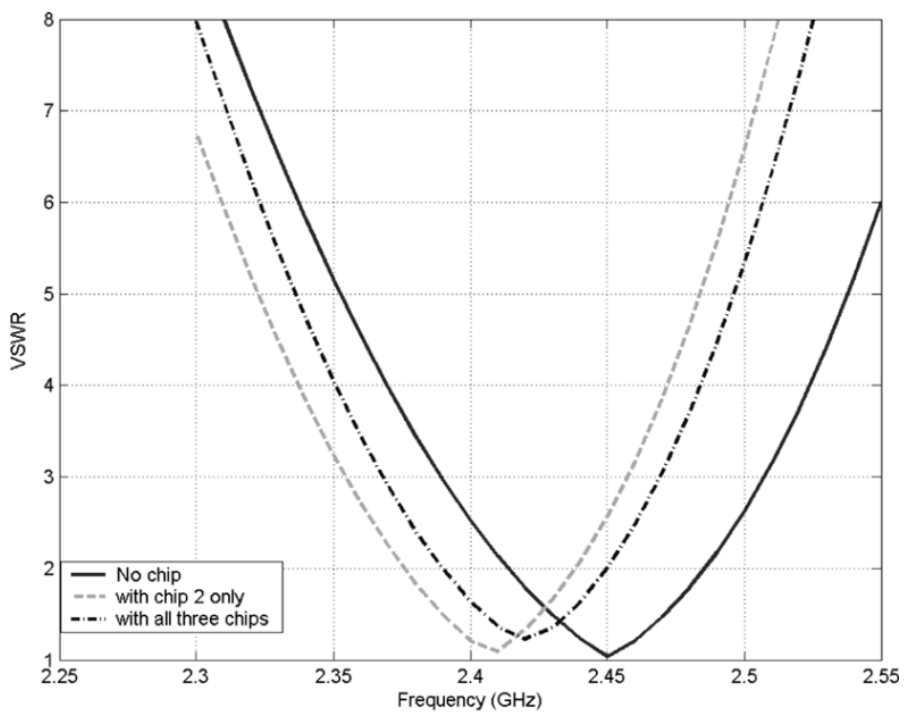

(b)

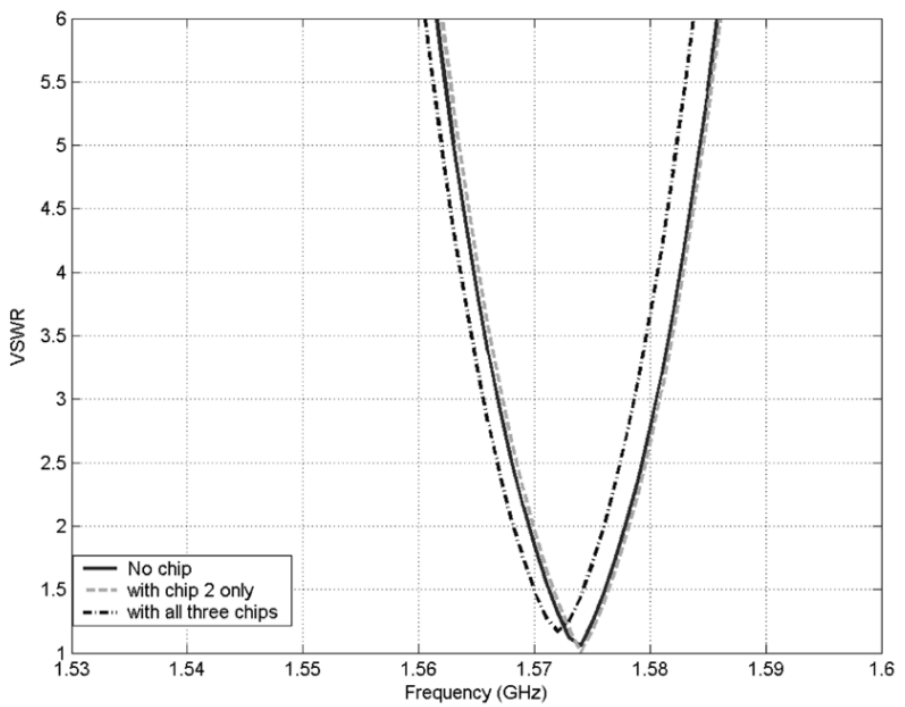

(d)

(c)

Fig. 12. Effect of surface mount chips on antenna performance. (a) Schematic view for the Bluetooth antenna with the chips (antenna height $=6.4 \mathrm{~mm}$ ). (b) Corresponding VSWR plot. (c) Schematic view for the GPS antenna with the chips (antenna height $=4.82 \mathrm{~mm}$ ). (d) Corresponding VSWR plots.

enough directionality at $1.575 \mathrm{GHz}$. Also the closely spaced elements with oppositely directed currents further degrades the gain. If antenna size has to be restricted peak gain can still be about $1 \mathrm{dBi}$. If antenna size can be made larger peak gain of the order of $2.5 \mathrm{dBi}$ is achievable.

\section{REFERENCES}

[1] M. A. Jensen and Y. Rahmat-Samii, "Performance analysis of antennas for hand-held transceivers using FDTD," IEEE Trans. Antennas Propag., vol. 42, no. 8, pp. 1106-1113, Aug. 1994.

[2] C. R. Rowell and R. D. Murch, "A capacitively coupled PIFA for compact mobile telephone handsets," IEEE Trans. Antennas Propag., vol. 45, no. 5, pp. 837-842, May 1997.

[3] K. L. Virga and Y. Rahmat-Samii, "Low-profile enhanced-bandwidth PIFA antennas for wireless communications packaging," IEEE Trans. Microw. Theory Tech., vol. 45, no. 10, pp. 1879-1888, Oct. 1997.

[4] L. Z. Dong, P. S. Hall, and D. Wake, "Dual-frequency planar inverted-F antennas," IEEE Trans. Antennas Propag., vol. 45, no. 10, pp. 1451-1458, Oct. 1997.
[5] C. R. Rowell and R. D. Murch, "A compact PIFA suitable for dualfrequency 900/1800 MHz operation," IEEE Trans. Antennas Propag., vol. 46, no. 4, pp. 596-598, Apr. 1998.

[6] P. Salonen, M. Kaskilammi, and M. Kivikosi, "Single-fed dual-band planar inverted-F antenna with U-shaped slot," IEEE Trans. Antennas Propagat., vol. 48, no. 8, pp. 1262-1264, Aug. 2000.

[7] S. C. K. Ko and R. D. Murch, "Compact integrated diversity antenna for wireless communications," IEEE Trans. Antennas Propag., vol. 49, no. 6, pp. 954-960, Jun. 2001.

[8] M. Ali, "Dual-band antenna having mirror image meandering segments and wireless communicators incorporating same," U.S. Patent 6184 836, Feb. 6, 2001.

[9] R. Sadler, G. Hayes, and M. Ali, "Compact, broadband inverted-F antennas with conductive elements and wireless communicators incorporating same," U.S. Patent 6218992 , Apr. 17, 2001.

[10] M. Ali, "Capacitively coupled plated antenna," U.S. Patent 6535 166, Mar. 18, 2003.

[11] R. Sadler, M. Ali, and G. J. Hayes, "Multi-frequency band inverted-F antennas with coupled branches and wireless communicators incorporating same," U.S. Patent 6563 466, May 13, 2003.

[12] M. T. Huynh and W. L. Stutzman, "Ground plane effects on PIFA antennas," in USNC/URSI Radio Sci. Meet. Dig., 2000, p. 223. 
[13] M. Ali, T. Sittironnarit, H.-S. Hwang, R. A. Sadler, and G. J. Hayes, "Wideband/dual-band packaged antenna for 5-6 GHz WLAN application," IEEE Trans. Antennas Propag., vol. 52, no. 2, pp. 610-615, Feb. 2004.

[14] M. F. Abedin and M. Ali, "Modifying the ground plane and its effect on planar inverted-F antennas (PIFA's) for mobile phone handsets," IEEE Antennas Wireless Propag. Lett., vol. 2, no. 15, pp. 226-229, 2003.

[15] M. Ali, G. J. Hayes, H.-S. Hwang, and R. A. Sadler, "Design of a multiband internal antenna for third generation mobile phone handsets," IEEE Trans. Antennas Propag., vol. 51, no. 7, pp. 1452-1461, Jul. 2003.

[16] M. Ali and G. J. Hayes, "Analysis of integrated inverted-F antennas for Bluetooth applications," in IEEE Antennas and Propagation Conf. Wireless Commun. Dig., Waltham, MA, Nov. 2000, pp. 21-24.

[17] - "A small printed integrated inverted-F antenna for Bluetooth application," Microw. Opt. Tech. Lett., vol. 33, no. 5, pp. 347-349, Jun. 5, 2002.

[18] M. Ali, R. A. Sadler, and G. J. Hayes, "A uniquely packaged internal inverted-F antenna for Bluetooth or wireless LAN application," IEEE Antennas Wireless Propag. Lett., vol. 1, no. 1, pp. 5-7, 2002.

[19] T. S. Rappaport, Wireless Communications, Principles and Practice. Englewood Cliffs, NJ: Prentice-Hall, 1996.

[20] J.-I. Moon and S.-O. Park, "Small chip antenna for 2.4/5.8-GHz dual ISM-band applications," IEEE Antennas Wireless Propag. Lett., vol. 2, no. 21, pp. 313-315, 2003.

[21] Geolocation and Assisted GPS, G. M. Djuknic and R. E. Richton.http://www.cs.huji.ac.il/course/2003/postPC/docs/Geolocation_assistedGPS.pdf [Online]

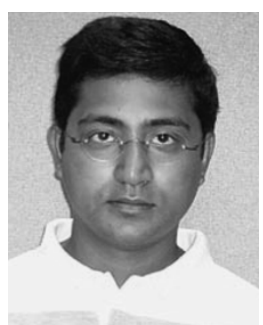

Khan M. Z. Shams was born in Faridpur, Bangladesh, in 1973. He received the B.Sc. and M.Sc. degrees in electrical engineering from the Bangladesh University of Engineering and Technology, Dhaka, Bangladesh, in 1997 and 2001, respectively. $\mathrm{He}$ is currently working toward the Ph.D. degree in electrical engineering at the University of South Carolina, Columbia.

He was a faculty member with the Bangladesh University of Engineering and Technology, Dhaka, from 1998 to 2003. His current research interests include design of microwave circuits and antennas for wireless communications, left-handed materials, and electromagnetic bandgap structures.

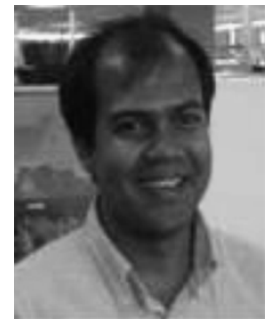

Mohammod Ali (M'93-SM'03) received the B.Sc. degree in electrical and electronic engineering from the Bangladesh University of Engineering and Technology, Dhaka, in 1987. He received the M.A.Sc. and $\mathrm{Ph} . \mathrm{D}$. degrees, both in electrical engineering, from the University of Victoria, Victoria, BC, Canada, in 1994 and 1997, respectively.

He was with the Bangladesh Institute of Technology, Chittagong, from 1988 to 1992. From January 1998 to August 2001, he was with Ericsson Inc., Research Triangle Park, NC, first as a Staff Engineer and then as a Senior Staff Engineer. Since August 2001, he has been with the Department of Electrical Engineering, University of South Carolina, Columbia, where currently he is an Assistant Professor. He had also held appointments as a Visiting Research Scientist with the Motorola Corporate EME Research Laboratory, Plantation, FL, during June-August 2004. He is the author/coauthor of more than 50 publications, holds four U.S. patents, and has several patent applications pending. His research interests include miniaturized packaged (embedded) antennas, electromagnetic bandgap (EBG) structures and their antenna applications, fractal and multiband antennas, wireless sensors, antennas and human body interaction, and microwave circuits using wide bandgap materials.

Dr. Ali is the recipient of the 2003 National Science Foundation Faculty Career Award. 